\title{
EHMTI-0242. Treating chronic tension-type headache with and without pericranial tenderness in association with a feeling of deontological guilt
}

\author{
E Guertzenstein
}

\author{
From 4th European Headache and Migraine Trust International Congress: EHMTIC 2014 \\ Copenhagen, Denmark. 18-21 September 2014
}

Chronic tension type headache is a disorder evolving from frequent episodic tension-type headache, with daily or very frequent episodes of headache, typically bilateral, pressing or tightening in quality and of mild to moderate intensity, lasting hours to days, or unremitting. The pain does not worsen with routine physical activity, but may be associated with mild nausea, photophobia or phonophobia. The feeling of deontological guilt occurs in individuals who, violating moral standards of the society in which they live, wonder how they were capable of such an attitude.

In this guilt feeling brain areas that mediate disgust are stimulated as the insulas.

The proposal was to evaluate the ineffectiveness of the treatments [antidepressants, anticonvulsants, betablockers, NSAIDs or acetaminophen, tramadol, acetylsalicylic acid, opioids, muscle relaxants, psychotherapy, acupuncture] to which that 21 patients (15 men and 6 women) aged 40 to 52 were submitted for 2 years after stealing money from their clients motivated by revenge. All patients were professionals, no previous psychiatric and neurologic disorders. The headache started in sequence to no evidence of the crime.

Counseling replaced treatments. The pain only remitted when each patient donated the stolen amount to charitable institutions to assuage guilt.

This study presents limitations: it is retrospective with a limited number of patients, showing a specific subpopulation of chronic tension-type headache. It is important to note that the criterion was limiter. This research supports a main conclusion that brain changes can be corrected, in

Divisão de Clínica Neurocirúrgica, Instituto de Neurologia / Hospital das Clínicas da Faculdade de Medicina da Universidade de São Paulo, São Paulo, Brazil

(c) 2014 Guertzenstein; licensee Springer. This is an Open Access article distributed under the terms of the Creative Commons Attribution License (http://creativecommons.org/licenses/by/2.0), which permits unrestricted use, distribution, and reproduction in any medium, provided the original work is properly cited. this case, with the recognition of error and change of conduct.

No conflict of interest.

Published: 18 September 2014

doi:10.1186/1129-2377-15-S1-C19

Cite this article as: Guertzenstein: EHMTI-0242. Treating chronic tensiontype headache with and without pericranial tenderness in association with a feeling of deontological guilt. The Journal of Headache and Pain 2014 15(Suppl 1):C19.

Submit your manuscript to a SpringerOpen ${ }^{\bullet}$ journal and benefit from:

- Convenient online submission

- Rigorous peer review

- Immediate publication on acceptance

- Open access: articles freely available online

- High visibility within the field

- Retaining the copyright to your article

Submit your next manuscript at springeropen.com 